\title{
An inner city home treatment service for acute psychiatric patients
}

\author{
Christine Dean, Senior Lecturer (correspondence); and Elaine Gadd, Senior \\ Registrar (Honorary Lecturer), Department of Psychiatry, Queen Elizabeth Hospital, \\ Birmingham B15 2TH
}

\section{Background}

Over the last ten years it has been shown that it is possible to treat the majority of patients with acute psychiatric illness in their own homes. Home treatment has been shown to produce a superior outcome to hospital care on measures of symptomatology, subsequent independent living and employment status (Hoult, 1986) self-esteem (Stein \& Test, 1980 ) and may decrease the need for re-admission. Additionally, home treatment decreases the burden felt by the relatives (Pai \& Kapur, 1982) and may enable them to cope better with the patient after the acute episode.

These results have been obtained from randomised controlled studies for which there were specific exclusion criteria, principally alcohol or drug dependence and organic brain syndromes.

To date there are no reports of the operation of a home treatment service in this country. We report such a service which is not a trial on a selected group of patients but the provision of psychiatric care to an unselected population of residents under the age of 65.

Central Birmingham psychiatric services are highly sectorised with each general psychiatry consultant being responsible for the under-65 population of one or two electoral wards C.D. is the consultant responsible for the inner city electoral ward of Sparkbrook. It has a population of about 25,000 (1981 Census). Over $50 \%$ of the inhabitants are from New Commonwealth or Pakistan, $11 \%$ from the Irish Republic and $35 \%$ from the United Kingdom. The population are mostly social class III manual, IV or V (only $12 \%$ in social class II or III non-manual). There is almost three times the national average rate of unemployment, $22.9 \%$ of males and $12.2 \%$ of females (Birmingham City Council, 1989) being unemployed. It is a very deprived area: 44 of the 51 enumeration Districts are in the worst $2.5 \%$ and all 51 are in the worst $10 \%$ of enumeration districts (in England and Wales), according to six Department of Environment indicators (1981 Census). The electoral ward has a Jarman Score (Jarman, 1984) of 62 (range -62.52 to +72.95 ) which puts it in the worst ten electoral wards . of the 9,265 in England and Wales. The population has a high level of psychiatric morbidity, in particular of severe psychiatric illness. The Sparkbrook population previously had been high users of in-patient facilities and there had traditionally been a high compulsory admission rate. In view of the nature of the population it was decided to try and deliver a service more suited to the particular needs of the community and to provide as much of the service as possible at home rather than in hospital. This type of service seemed particularly appropriate for the Asian patients who were especially reluctant to go into hospital and who usually had supportive extended families.

Prior to setting up the home treatment service the District had obtained funding from the Good Practices in Mental Health initiative for a resource centre in Sparkbrook. This resource centre (initially in a temporary location) provides the centre for the home treatment service staff and the focal point for referrals. The resource centre is run by a multidisciplinary team and is a joint health/social services venture. The manager is a social worker and the deputy manager is a charge nurse. There is an occupational therapist employed by the health service and two instructors employed by social services. The district psychologist does one or two sessions at the centre and a psychology technician is based there. The resource centre provides a five day a week (including Bank Holidays) 'drop-in' service for patients with chronic mental illness and specific group activities for such patients and for patients with more minor illnesses. It also provides a service, where required, for patients who are acutely ill and on home treatment, and relative support groups.

Initially there were three community psychiatric nurses working in Sparkbrook. To these have been added two community psychiatric nurses specifically for the home treatment service and two nursing assistants. There are also two social workers who work in the electoral ward. The consultant and senior registrar provide a total of 11 sessions to the electoral ward and there is a full-time registrar. Five of the staff speak Asian languages. The resource centre and the home treatment service are run very flexibly so 
that all staff work in the centre and in the community depending on the needs of individual clients.

\section{How the home treatment service operates}

The service accepts referrals from any agency, general practitioner, health visitor, patient, relative etc. Urgent referrals are seen as soon as possible and certainly on the day of referral by a nurse and a doctor. Wherever possible the patients are assessed initially by at least one member of staff who speaks their language. Thereafter the staff have a mixed case load but always have the benefit of advice from someone who speaks the appropriate language if this is required. All the staff carry a limited repertoire of drugs (thioridazine, chlorpromazine, haloperidol, amitriptyline, procyclidine, fluphenthixol decoanate) so that initial treatment can be started immediately if this is required. If the patient is regarded as suitable for 'home treatment' they have a full 'work up' as if they were in hospital with a full history, case summary and physical examination.

At this time any investigations required are organised. The doctor carries a bag with all the necessary instruments, venepuncture equipment and request forms, medication and a prescription pad. A folder is made up for each home treatment patient containing continuation sheets, physical examination sheet and prescription card. This is left in the patient's home. On the cover are instructions about how to 'bleep' the $24 \mathrm{hr}$ on call home treatment nurse. Any staff member (whatever discipline) records their assessment at each visit on the continuation sheets. At the end of 'home treatment' all these records are filed in the patient's main hospital records. Initially patients are visited at least once daily by a doctor and a nurse and often in the first few days they require visits several times a day. Medication is dispensed daily where this is necessary for compliance or safety reasons. The nursing assistants sometimes spend several hours at a time in the patient's house supporting the relatives or allowing them to be out of the house for a while. Patients are reviewed twice weekly in a multidisciplinary meeting and at that time a decision is made whether to continue patients on home treatment or to discharge. At any time a decision can be made to admit patients to hospital if home treatment is no longer regarded as appropriate.

At the time of discharge from home treatment all patients have a discharge plan and they are followed up at out-patient clinics which are run at the resource centre or visited on a regular basis at home if they are not able to attend. They and their relatives are asked to contact us immediately if there are any early signs of illness relapse. Patients are also offered whatever service they require from the centre, drop-in facility, group activities, social work help etc.
This paper reports the first full year (October 1987 to September 1988) of the 'home treatment' service. At this time the resource centre was only operating in a rented room in a community centre three days a week and the 24 hour on call had not been instigated.

\section{Findings}

For the period in question we have compared the characteristics of those patients who were admitted (including those who had failed on home treatment or were regarded as unsuitable after initial assessment) from the Sparkbrook electoral ward, with those who had home treatment alone. We then examine the characteristics of patients where home treatment failed and the patient had to be admitted.

There was no significant difference between those admitted and those who had home treatment alone in terms of sex, age or ethnic group. However there was a difference in marital status with those admitted being significantly more likely to be single $(27$ [ $50 \%]$ cf $10[26 \%] ; \chi^{2}=7.46,2$ d.f.; $P<0.05$ ). There was no difference in the DSM-IIIR diagnoses between admissions and home treatment patients but there was a tendency for the home treatment group to have more patients with a non-psychotic diagnosis (Table I).

We also examined a number of other factors which may have influenced whether or not patients were admitted or put on home treatment: location of assessment, time of assessment, whether or not the patient had a previous admission, had previously been compulsorily detained and whether they lived alone. The location of assessment was very important in determining the location of initial treatment. Thirty-eight (78\%) of patients who were initially put on home treatment had their assessment at home and $26(60 \%)$ of patients initially admitted had their assessment at the hospital $\left(\chi^{2}=49.2,3\right.$ d.f.; $P<0.001)$. The time of assessment is also important with more of the admission group presenting out of hours (18 [42\%] cf $2[4 \%] ; \chi^{2}=17,1$ d.f.; $\left.P<0.001\right)$. There were no significant differences in the numbers of patients living alone, presenting with violence or self-harm, having a previous admission or a previous detention.

Seventeen out of the $55(31 \%)$ patients who were assessed for home treatment were admitted, six because they were unsuitable and eleven because home treatment could not be continued. This group did not differ in terms of diagnosis or demographic factors from those not admitted. However the numbers are too small for statistical analysis and it seems more important to examine the reasons for failure. The six patients who were regarded as unsuitable for home treatment included three in police custody (the police insisted on their going to hospital if charges were to be dropped), a Caribbean patient 
TABLE I

DSM III-R diagnosis n (\%)

\begin{tabular}{|c|c|c|c|c|}
\hline Diagnosis & $\begin{array}{l}\text { DSM III-R } \\
\text { codes }\end{array}$ & $\begin{array}{c}\text { Admissions including } \\
\text { home treatment } \\
\text { failures } \\
\mathrm{n}=54\end{array}$ & $\begin{array}{c}\text { Home treatment } \\
\text { successes } \\
\mathrm{n}=38\end{array}$ & $\begin{array}{c}\text { Home treatment } \\
\text { failures } \\
n=17\end{array}$ \\
\hline Manic & $\begin{array}{l}296.41-0.45 \& \\
296.61-0.62\end{array}$ & $12(22)$ & $8(21)$ & $5(29)$ \\
\hline Depressive & $\begin{array}{l}296.52-0.54 \\
296.32-0.34 \\
296.22-0.25 \\
311.00\end{array}$ & $17(31.5)$ & $10(26.5)$ & $5(29)$ \\
\hline Schizophrenia & $295.1-0.7$ & $8(15)$ & $11(29)$ & $4(24)$ \\
\hline Other psychoses & $\begin{array}{l}297.1 \\
298.1-0.9\end{array}$ & $1(2)$ & $3(8)$ & $0(0)$ \\
\hline Substance abuse & $\begin{array}{l}291.0-0.8 \\
305.0-0.9 \\
291.8\end{array}$ & $5(9)$ & $3(8)$ & $1(6)$ \\
\hline Neuroses & $300-300.4$ & $4(7)$ & $0(0)$ & $1(6)$ \\
\hline Adjustment disorder & $309.0-300.9$ & $2(4)$ & $0(0)$ & $0(0)$ \\
\hline Eating disorder & 307.5 & $3(5.5)$ & $0(0)$ & $0(0)$ \\
\hline Presenile dementia & 290.1 & $0(0)$ & $1(2.5)$ & $0(0)$ \\
\hline \multirow[t]{3}{*}{ Other } & 313.8 & $2(4)$ & $2(5)$ & $1(6)$ \\
\hline & V71.01 & & & \\
\hline & V15.81 & & & \\
\hline
\end{tabular}

with Capgras, a suicidal patient with delusions of jealousy and one with a fractured tibia and fibula.

The eleven patients who failed on home treatment included four aggressive manic patients, two of whom were women who had small children at home; the other two were aggressive towards their family members. Three were severely depressed patients who stopped eating and drinking and refused oral medication. One patient was schizophrenic with delusional jealousy and was aggressive towards his wife. One patient had severe obsessive-compulsive disorder with serious self neglect and an unsupportive family. One schizophrenic patient lived alone and was uncooperative with medication and required admission to a medical ward for heart failure. One schizophrenic patient with severe Parkinson's disease and poor family support needed to be admitted for mobilisation.

The factors influencing admission seem to be social or due to concurrent physical illness rather than diagnostic factors. Whether or not our type of service could operate as well in other areas remains to be seen. The catchment area is very compact making frequent visiting feasible and the large proportion of Asian patients with their extended families may be partly the reason for success. However the population, on the whole, is very deprived and some patients treated at home lived alone and had poor social support.

\section{Acknowledgement}

We would like to thank Dr Stuart Cumella for providing data from the Central Birmingham Case Register.

\section{References}

BIRMINGHAM CIrY COUNCIL (1989) Ward Unemployment Summary for the year to January 1989. Information Group, Birmingham.

HoulT, J. (1986) Community care of the acutely mentally ill. British Journal of Psychiatry, 149, 137-144.

JARMAN, B. (1984) Underprivileged areas: validation and distribution of scores. British Medical Journal, 289, 1587-1592.

PAI, S. \& KAPUR, R. L. (1982) Impact of treatment intervention on the relationship between dimensions of clinical psychopathology, social dysfunction and burden on the family of psychiatric patients. Psychological Medicine, 12, 651-658.

Stein, L. I. \& TeST, M. A. (1980) Alternative to mental hospital treatment. I. Conceptual model, treatment programme and clinical evaluation. Archives of General Psychiatry, 37, 392-397. 